\title{
Consciência morfológica: que papel exerce no desempenho ortográfico e na compreensão de leitura?
}

\author{
Sandra Regina Kirchner Guimarães ${ }^{a 1}$, Fraulein Vidigal de Paulab ${ }^{b}$ Márcia Maria Peruzzi Elia da \\ Motac, Viviane do Rocio Barbosa ${ }^{a}$

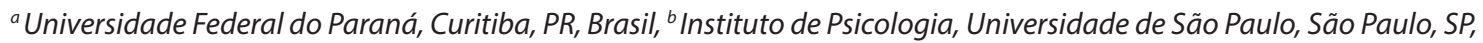 \\ Brasil, ' Universidade Salgado de Oliveira, Rio de Janeiro, RJ, Brasil e Universidade do Estado do Rio de Janeiro, RJ, Brasil
}

\begin{abstract}
Resumo: A consciência morfológica diz respeito à habilidade para refletir sobre as menores unidades de sentido de uma língua e utilizá-las intencionalmente na estruturação e reconhecimento das palavras. São apresentados argumentos que apoiam a ideia de que no português, como em outras línguas alfabéticas, a consciência morfológica contribui tanto para a compreensão de leitura como para o desempenho. Participaram 72 alunos de $3^{\circ}, 4^{\circ}$ e $5^{\circ}$ anos de uma escola pública (Curitiba-PR), separados em dois grupos de desempenho ortográfico para cada um dos anos letivos. A coleta de dados envolveu a aplicação de sete instrumentos de avaliação, sendo: um de ortografia, três de consciência morfológica e dois de compreensão de leitura de texto. A análise dos dados empíricos apresentados mostra que o desempenho nas tarefas de avaliação da consciência morfológica (flexional e derivacional) contribui significativamente para explicar a variância de desempenho dos participantes em ambas as habilidades, ou seja, compreensão de leitura e escrita ortográfica.
\end{abstract}

Palavras-chave: linguagem escrita, escrita de histórias, crianças, produção textual, avaliação.

A escrita requer, por parte de quem escreve, o desenvolvimento de diversas habilidades cognitivas e linguísticas relativas ao sistema de escrita. Além destas, as habilidades metalinguísticas apresentam-se como primordiais para a aprendizagem formal na escola devido a sua natureza consciente (Kato, 1999). Ou seja, as habilidades metalinguísticas permitem aos aprendizes a gestão consciente (reflexão e controle deliberado) dos objetos linguísticos e de sua utilização.

Neste artigo examina-se as relações entre a consciência morfológica, o desenvolvimento do desempenho ortográfico e a compreensão de leitura. Esta é uma questão importante no estudo da aprendizagem das línguas alfabéticas como o inglês, o francês ou o português, pois seus sistemas de escrita representam graficamente tanto fonemas como morfemas. Morais, Alegria e Content (1987) explicam que os fonemas não possuem uma realidade concreta, por isso sua manipulação exige algum modo de materialização, 0 que é possibilitado pelas letras que os representam. Daí a importância da consciência fonológica para a aquisição e aperfeiçoamento da leitura e da escrita, demonstrada por diversos estudos no Brasil e no mundo (Bradley \& Bryant, 1983; Capovilla \& Capovilla, 2000; Cardoso-Martins, 1995; Guimarães, 2003; Maluf \& Barrera, 1997; Morais et al., 1987; Roazzi \& Dowker, 1989; Tunmer, 1990).

No entanto, nem todas as ortografias são inteiramente previsíveis a partir das correspondências entre fonemas e letras. Isso é verdadeiro notoriamente para as ortografias

1 Autor correspondente: srkguimaraes@uol.com.br "irregulares" como a do inglês e, em certa medida, do francês. Essas ortografias chamadas "profundas" ou "opacas" não são totalmente transparentes ao nível da previsibilidade das relações grafema-fonema porque são regidas não apenas pela fonologia, mas também pela morfologia (Seymour, Aro, \& Erskine, 2003).

A morfologia refere-se aos padrões de formação de palavras com base em morfemas, que, por sua vez, podem ser definidos como as menores unidades significativas da língua (Rocha, 2008). Em inglês, um exemplo típico de grafia morfologicamente regulada é a ortografia dos verbos regulares que, no pretérito, são marcados pelo sufixo - ed. Nestes casos, a sequência sonora /ed/ nunca é pronunciada, pois a pronúncia do final do verbo depende do ambiente sonoro que precede o sufixo. Portanto, embora a grafia (marcação do pretérito) destes verbos seja sempre a mesma, a pronúncia difere conforme a raiz do verbo. Assim, se a raiz do verbo termina em /s/, o som final é/t/, por exemplo: diz-se /kisst/ para kissed; se a raiz do verbo termina em/t/, o som final é/id/, por exemplo: diz-se /testid/ para tested. Como explica Sterling (1991), em inglês, muitas "irregularidades" do ponto de vista fonêmico são "regularidades" do ponto de vista morfêmico. Neste sentido, Mota $(2008 b$, 2010) exemplifica que a palavra heal, que rima com /il/, e a palavra health, que rima com /elf/, são escritas da mesma forma devido a sua origem semântica, embora sejam pronunciadas de maneira diferente.

Tradicionalmente, os linguistas reconhecem duas grandes classes de morfemas no que diz respeito a sua posição na palavra: as raízes e os afixos. As raízes (morfemas lexicais ou lexemas) são portadoras da significação básica das palavras de um grupo lexical e constituem o núcleo 
comum das palavras do grupo. Assim, em estudar, estudo, estudante, estudantil, estudável e reestudar, a raiz é estud-. Os afixos, morfemas sem autonomia morfossintática, podem ser de dois tipos: prefixos, quando adicionados antes da raiz, ou sufixos, quando adicionados depois da raiz (Laroca, 2005; Silva \& Koch, 2005). Em termos de implicações ortográficas, a formação de palavras por acréscimo de sufixo pode alterar mais frequentemente a grafia do lexema do que a formação por prefixação, como no exemplo: picar/repicar/repique.

Em relação à função na palavra, os afixos podem representar um papel derivacional ou um papel flexional. Os morfemas derivacionais podem ser encontrados antes (prefixo) ou depois do morfema lexical (sufixo), alterando seu sentido ou classe gramatical inicial e permitindo a geração ou formação de novas palavras na língua. Por exemplo, nos pares: fazer/refazer, ou fazer/desfazer, o sentido inicial da palavra fazer foi alterado pelos prefixos re- ou des-, gerando palavras com significados diferentes na língua. $\mathrm{O}$ morfema derivacional pode modificar, além do sentido, a classe gramatical da palavra. Por exemplo, no par: jogar/ jogador, a palavra jogador se relaciona por derivação com a palavra jogar, pelo acréscimo do sufixo derivacional -dor. Como as derivações interferem na estrutura das palavras, pode haver uma instabilidade semântica (por exemplo: correr/corredor, em que corredor pode significar "aquele que corre", mas também "lugar de passagem"). Assim, pode-se dizer que os morfemas derivacionais desempenham uma função semântico-lexical.

Os morfemas flexionais são sempre sufixos, ou seja, só podem aparecer no final da palavra. Eles alteram o morfema lexical (ou raiz) para que este se adapte ao contexto sintático da palavra. Podem ser acrescentados a substantivos e adjetivos para flexionar o gênero (masculino e feminino, como em menin-o e menin- $a$ ), o grau (diminutivo e aumentativo, como em menin-inh-o/menin-ão) $)^{2}$ e número (singular e plural, como em menino e menino-s), mas também a verbos, para flexioná-lo em termos de modo (a atitude de certeza, incerteza, impossibilidade, solicitação etc) e tempo (em que ocorre a ação verbal), além de número (singular e plural) e pessoa (o sujeito do enunciado da ação verbal). (Silva \& Koch, 2005). Portanto, é possível dizer que a flexão e os morfemas flexionais têm caráter morfossintático, pois cumprem uma exigência de concordância nominal ou verbal, de acordo com a necessidade imposta pela frase.

Nessa ordem de esclarecimentos, o estudo da consciência morfológica pode incluir medidas distintas de vários tipos de morfemas envolvidos na formação das palavras (lexicais, derivacionais e flexionais), podendo-se buscar correlações entre a consciência de tipos específicos de morfemas e a capacidade de leitura e de escrita.

Entretanto, ao revisar os principais modelos de aprendizagem da linguagem escrita identificam-se duas

2 Há controvérsias entre os gramáticos e linguistas a respeito do grau ser uma alteração derivacional ou flexional na palavra (Câmara Jr, 1988). visões sobre o desenvolvimento da consciência morfológica e sua relação com a escrita. Na primeira, defende-se que a consciência morfológica se desenvolve tardiamente por volta do terceiro ano e, na segunda, desde os anos iniciais. $\mathrm{O}$ estudo apresentado neste artigo não contradiz a segunda, mas traz evidências que fortalecem a primeira hipótese de que a consciência morfológica contribui para a escrita ortográfica e a compreensão das crianças de $3^{\circ}, 4^{\circ}$ e $5^{\circ}$ ano.

Nunes, Bryant e Bindman (1997) estudaram o desenvolvimento do conhecimento da morfologia flexional em crianças inglesas do ensino fundamental. Os autores mostraram que as crianças parecem passar por uma sequência de estágios no conhecimento de como as palavras são formadas. A pesquisa concentrou-se na aquisição da escrita de morfemas como o -ed no inglês, e mostrou que antes que as crianças possam escrever palavras morfologicamente complexas, que fogem aos padrões de correspondência entre letra e som do inglês, elas precisam ter entendido o princípio alfabético, ou seja, como as letras correspondem aos sons da fala.

O estudo de Nunes et al. (1997) corrobora os principais modelos de desenvolvimento da escrita que vigoravam na época. Esses modelos trabalham com a ideia de que o desenvolvimento da escrita ocorria em estágios e de que o processamento das palavras em morfemas ocorre após a aquisição do princípio alfabético (Frith, 1985; Marsh, Friedman, Welch, \& Desberg, 1981). Hoje, os modelos de Marsh et al. (1981) e Frith (1985) têm sido substituídos por outros mais atuais.

É possível que o desenvolvimento da escrita possa não ocorrer em estágios e que também não seja necessário que as crianças tenham adquirido o princípio alfabético antes de usar informações morfológicas. Colé, Marec-Breton, Royer e Gombert (2003) deram a crianças francesas, nos anos iniciais de aprendizagem da leitura, quatro grupos de palavras: morfologicamente complexas (ex., banheiro: banho+eiro); com a mesma sequência de letras, mas morfologicamente simples (ex., dinheiro); pseudopalavras morfologicamente complexas (ex., linheiro: linho+eiro); pseudopalavras não sufixadas (ex., binheiro). Apesar de as palavras no estudo terem as mesmas características fonológicas e número de letras, as crianças cometeram menos erros lendo as palavras morfologicamente complexas do que as palavras simples. Estes resultados indicam um efeito facilitador da estrutura morfológica no reconhecimento de palavras desde os anos iniciais de escolarização. O mesmo pode-se observar em português nos resultados preliminares do estudo de Ferraz, Salomão e Paula (2011), com crianças do $2^{\circ}$ e $4^{\circ}$ ano do ensino fundamental.

Mota (2008a), estudando crianças brasileiras do $2^{\circ}$ e de $3^{\circ}$ ano, aplicou seis tarefas de consciência morfológica. Cinco envolviam julgamento de respostas corretas e uma era de produção. Os resultados mostraram que, para as quatro primeiras tarefas de julgamento, as crianças do $2^{\circ}$ ano atingiram níveis de acerto bem acima do nível de resposta ao acaso. Para uma das tarefas de julgamento e para a de produção, os níveis de acerto foram de $63 \%$ e $52 \%$, 
respectivamente. Esses resultados mostram que crianças com dois anos de escolarização formal são capazes de fazer julgamentos sobre a morfologia da língua. Mesmo nas tarefas de produção as crianças eram capazes de produzir respostas corretas em pelo menos metade dos itens de produção. Quando a tarefa é simplificada, o índice de acerto é acima do nível de resposta ao acaso. Resultados similares foram repetidos em Mota et al. (2011).

Contudo, embora muitos estudos deem suporte à ideia de que o desenvolvimento de habilidades para manipulação de conhecimento morfológico encontra-se associado aos indicadores de proficiência em leitura e escrita, grande parte deles investigou os momentos mais avançados do processo de aprendizagem da língua escrita, quando o aprendiz já teria automatizado o reconhecimento e uso das relações grafo-fonológicas, podendo ocupar-se das dimensões de sentido da língua (para uma revisão crítica destes estudos ver Colé et al., 2003; Deacon \& Bryant, 2005).

Em língua inglesa, entre os primeiros estudos que dão suporte à ideia de que a consciência morfológica está relacionada à aquisição e/ou ao aperfeiçoamento da leitura e da escrita estão aqueles realizados por Joanne Carlisle. Em 1995 a autora publicou um estudo longitudinal por meio do qual investigou o desenvolvimento metalinguístico em crianças no início da escolarização formal e verificou uma relação significativa entre a consciência morfológica e a aquisição de habilidades em leitura (Carlisle, 2005). No ano seguinte, publicou dados de um estudo exploratório sobre o emprego de palavras morfologicamente complexas por crianças de $2^{\circ}$ e $3^{\circ}$ anos com e sem problemas de aprendizagem. Seus resultados registram que os dois grupos do $3^{\circ}$ ano (com e sem problemas de aprendizagem) foram mais precisos na utilização de flexões, derivações e palavras compostas (Carlisle, 1996).

Outros estudos realizados na língua inglesa defendem igualmente que a habilidade de refletir sobre os morfemas das palavras está associada tanto ao desempenho em leitura (Carlisle, 2000; Deacon \& Kirby, 2004; Nagy, Berninger, \& Abbot, 2006) como ao desempenho em escrita (Carlisle, 1988, 1996; Nunes et al., 1997).

Também desenvolvido com participantes de língua inglesa, o estudo realizado por Deacon e Bryant (2005) examinou os efeitos do conhecimento de sufixos na escrita de crianças. Os resultados dessa investigação apontam que as crianças de 5 a 8 anos demonstraram ter consciência das flexões, mas não das derivações. Os autores concluíram que é mais difícil para as crianças entender as relações morfêmicas nas derivações do que nas flexões, devido ao fato de que na morfologia derivacional há uma mudança na classe gramatical das palavras morfologicamente complexas, o que não ocorre na morfologia flexional.

Além desses, destacam-se ainda dois estudos apresentados em publicações recentes. Um deles, de autoria de Bowers e Kirby (2010), investigou os efeitos de 20 sessões de intervenção focalizando a estrutura morfológica das palavras sobre o conhecimento de vocabulário de quatro turmas de alunos do $4^{\circ}$ e $5^{\circ}$ ano. Os resultados do estudo mostraram efeitos significativos das instruções realizadas sobre a análise morfológica e a aquisição de palavras (vocabulário) que foram diretamente ensinadas e, também, de novas palavras formadas a partir de bases que foram ensinadas no trabalho com outras derivações; mas não com palavras formadas com bases não trabalhadas. Em outro estudo, de Deacon, Kirby e Bell-Casselman (2009), os pesquisadores realizaram uma investigação longitudinal que avaliou diferentes habilidades cognitivas em crianças de 7 anos de idade (inteligência verbal e não verbal, nomeação rápida, memória verbal de curto prazo, consciência fonológica e consciência morfológica) e o impacto dessas habilidades sobre o desempenho geral das crianças na escrita de palavras isoladas dois anos mais tarde. Os resultados apresentados mostram que a consciência morfológica é uma variável importante na determinação do desempenho futuro em escrita geral (e não apenas na escrita de morfemas específicos), e que a contribuição da consciência morfológica é independente da contribuição das outras variáveis avaliadas. Os resultados destes estudos apontam a necessidade de novas investigações que possam esclarecer com maior precisão o papel da consciência morfológica na aquisição e/ou aperfeiçoamento do vocabulário, da leitura e escrita de palavras com morfemas específicos (aprendidos a partir de instrução precisa), e sobre o desenvolvimento da linguagem escrita de modo geral, o que alimenta reflexões tanto teóricas, do ponto de vista do aperfeiçoamento dos modelos de representação do uso e da aprendizagem da língua escrita, como educacionais, no que diz respeito à facilitação das aprendizagens por meio do planejamento de ensino baseado em evidências científicas.

O português é uma língua alfabética mais transparente do que a língua inglesa, ou seja, apresenta maior grau de correspondência entre letras e sons da fala, o que sugere uma contribuição menos significativa do processamento morfológico na aquisição da linguagem escrita (Mota et al., 2008). Contudo, na última década, estudos em língua portuguesa têm apresentado evidências de uma relação entre a consciência morfológica e o desempenho na linguagem escrita. Com efeito, Queiroga, Lins e Pereira (2006), em uma pesquisa que envolveu 120 alunos do $3^{\circ}$ e $5^{\circ}$ anos de escolas públicas e particulares, investigaram a relação entre a consciência morfossintática e o desempenho ortográfico. Seus resultados mostraram um efeito preditor do conhecimento morfossintático sobre o desempenho ortográfico, bem como uma evolução entre as séries na explicitação do conhecimento morfossintático e na escrita de palavras e pseudopalavras. As autoras concluíram que o conhecimento morfossintático possibilita às crianças uma maior compreensão dos processos de formação de palavras e, consequentemente, maior domínio ortográfico.

Paula (2007), com o objetivo de estudar conhecimentos implícitos e explícitos sobre morfologia, derivacional e flexional, e como estes se relacionam à leitura e escrita, em um estudo transversal, investigou crianças brasileiras de uma escola particular, de $2^{\circ}, 4^{\circ}, 6^{\circ}$ e $8^{\circ}$ anos (antigas $1^{\mathrm{a}}, 3^{\mathrm{a}}, 5^{\mathrm{a}}$ e $8^{\mathrm{a}}$ séries). Seus resultados sugerem que 
as crianças de $2^{\circ}$ ano possuem conhecimentos implícitos em morfologia derivacional. Nos demais anos, observou-se melhor desempenho em tarefas de conhecimento explícito (consciência morfológica), e quanto mais desenvolvida a consciência morfológica, mais esta se apresenta correlacionada aos avanços em leitura e escrita.

Nessa mesma vertente, Mota, Aníbal e Lima (2008) realizaram uma investigação com o objetivo de verificar a contribuição do processamento da morfologia derivacional para a leitura e a escrita no português, analisando também se esta contribuição é dependente da consciência fonológica, ou seja, subproduto do processamento fonológico. Seus resultados mostram que a habilidade de refletir sobre os morfemas contribui tanto para a leitura como para a escrita, sendo essa contribuição até certo ponto independente do processamento fonológico.

Ainda no contexto do português do Brasil, destacase o estudo de Guimarães (2011), realizado com 40 crianças de $4^{\circ}$ e $5^{\circ}$ anos do ensino fundamental, com o objetivo de analisar a concepção de "palavra" de alunos do $2^{\circ}$ ciclo do ensino fundamental e investigar como a capacidade de segmentação gráfica dessas crianças relaciona-se com a consciência morfossintática e com o desempenho em tarefas de escrita e de compreensão de leitura. Os resultados do estudo mostram relações significativas entre a consciência morfossintática, a capacidade de segmentação convencional de palavras escritas e a compreensão de leitura.

Neste sentido, em relação às duas visões concernentes ao desenvolvimento da consciência morfológica e seu papel em relação ao desenvolvimento da leitura e escrita, evidencia-se que esta começa a se desenvolver nos primeiros anos escolares. No entanto, sua contribuição para a leitura e a escrita, tende a se tornar mais expressiva nos anos mais avançados quando o aprendiz se depara com desafios que demandam mais reflexão sobre a língua, como, por exemplo, sobre os fatores que orientam a escrita ortográfica. Resta em aberto, no entanto, o conhecimento sobre como estas contribuições se dão para aspectos específicos tanto da escrita quanto da leitura, em diferentes etapas do processo de escolarização.

É neste contexto teórico que este artigo se insere, tendo como objetivo central verificar as relações entre o desempenho de alunos do $3^{\circ}, 4^{\circ}$ e $5^{\circ}$ anos do ensino fundamental em tarefas de avaliação da consciência morfológica, ortografia e compreensão ou atribuição de sentido na leitura.

\section{Método}

Os participantes da presente pesquisa fazem parte de um estudo longitudinal que investiga como o desempenho em leitura e escrita de alunos do $3^{\circ}, 4^{\circ}$ e $5^{\circ}$ anos do ensino fundamental relaciona-se com diferentes habilidades linguísticas. A amostra consiste de 72 alunos de uma escola pública no município de Curitiba (PR), sendo 24 alunos de cada ano investigado $\left(3^{\circ}, 4^{\circ}\right.$ e $5^{\circ}$ anos). Foi indicada pela escola uma turma de cada ano escolar, com o mesmo número de alunos. Nesta escola, os alunos matriculados no $3^{\circ}$ ano em diante já dominavam o princípio alfabético e estavam na via do desenvolvimento da proficiência ortográfica. Em outras palavras, este estudo não enfatiza a influência da morfologia na aquisição inicial da linguagem escrita, mas avalia possíveis relações entre o processamento de morfemas e o aumento do domínio na leitura e na escrita.

Os participantes foram divididos em seis grupos, ou seja, os alunos de cada ano foram separados em dois grupos (A e B), de acordo com seu desempenho ortográfico na reprodução escrita da história "O pote vazio" (Demi, 2000): "A" menor desempenho e "B" maior desempenho. No período em que os dados apresentados foram coletados a média de idade dos alunos de cada um dos grupos era a seguinte: $3^{\circ} \mathrm{A}-8$ anos e 3 meses, $3^{\circ} \mathrm{B}-8$ anos e 4 meses, $4^{\circ} \mathrm{A}-9$ anos e 2 meses, $4^{\circ} \mathrm{B}-9$ anos e 3 meses, $5^{\circ}$ ano (A e B) -9 anos e 11 meses.

De acordo com os dados fornecidos pelas equipes pedagógico-administrativas das escolas, os alunos são oriundos de famílias com renda familiar de dois a cinco salários mínimos. Além disso, a escolaridade média de seus pais é a de ensino fundamental. Com base nesses dados, considerou-se que não havia variação socioeconômica significativa entre os participantes. Destaca-se, ainda, que a inclusão dos alunos no estudo dependeu da autorização dos responsáveis por meio do Termo de Consentimento Livre e Esclarecido. A pesquisa foi aprovada pelo Comitê de Ética em Pesquisa do Setor de Saúde da UFPR. Registro CEP/ SD: 1280.205.11.12 CAAE: 0196.0.091.000-11

\section{Instrumentos}

O presente estudo foi baseado em três tipos de instrumentos de coleta de dados:

\section{Reprodução escrita de história}

O objetivo desta tarefa foi obter um texto escrito de todos os alunos no qual reproduzissem a história "O pote vazio" (Demi, 2000). A partir dos textos produzidos foi verificado o desempenho ortográfico dos participantes, calculando-se o percentual de palavras escritas de forma ortograficamente correta. A porcentagem de acertos ortográficos de cada participante foi calculada levando-se em consideração o total de palavras escritas ao se reproduzir a história, ou seja, o número de acertos foi multiplicado por cem e dividido pelo número total de palavras escritas.

Esta tarefa foi realizada na própria sala de aula dos participantes e ministrada pelas professoras regentes. Todas as professoras desenvolveram a atividade da mesma maneira, ou seja, primeiro leram a história, depois discutiram o conteúdo da mesma com os alunos e, por último, solicitaram a reprodução escrita da história.

\section{Tarefas de avaliação da consciência morfológica}

Para avaliar a consciência morfológica foram aplicadas três tarefas (de categorização gramatical, de morfologia 
flexional e de morfologia derivacional), todas já utilizadas em estudos anteriores (Paula, 2007; Sá, 2006). A primeira tarefa (de categorização gramatical) foi aplicada na forma original, as outras duas tarefas sofreram pequenas variações, ou seja, aumentou-se a quantidade de exemplos no treino para garantir boa compreensão aos participantes e foram substituídos alguns itens que continham palavras pouco frequentes e familiares aos participantes. A primeira tarefa foi aplicada aos alunos individualmente e as outras duas em pequenos grupos (geralmente com 4 alunos de cada vez).

Além disso, salienta-se que as tarefas aplicadas envolvem diferentes modalidades de pensamento, sendo a primeira relacionada à formação e categorização de conceitos gramaticais, enquanto as outras duas envolvem formação de julgamento e tomada de decisão. No entanto, as três apresentam um nível de exigência de esforço cognitivo semelhante, na medida em que a boa resposta já está presente na própria tarefa, pois a demanda cognitiva é relativamente baixa e não exige do examinando a produção da resposta correta. O que deve diferenciar o desempenho nas tarefas refere-se sobretudo ao conhecimento linguístico avaliado.

\section{Tarefa de categorização gramatical (Sá, 1999, 2006)}

Nesta tarefa são apresentadas aos participantes (em pequenos cartões) 15 palavras de três categorias gramaticais diferentes: cinco substantivos, cinco adjetivos e cinco verbos. Em seguida, o examinador solicita ao aluno que forme três grupos de palavras. Se o aluno conseguir distribuir as palavras corretamente, ou seja, formar os três grupos de acordo com as classes gramaticais, a tarefa é encerrada.

Uma segunda oportunidade é oferecida aos participantes que não conseguirem classificar as palavras em categorias gramáticas. Nesta segunda etapa, o examinador seleciona três palavras - um verbo, um adjetivo e um substantivo - e pede ao aluno que coloque todas as ações junto ao verbo, todos os nomes junto ao substantivo e todas as qualidades junto ao adjetivo. A tarefa é composta de 15 itens (Assim, 15 acertos $=100 \%, 14$ acertos $=93,33 \%$ ).

\section{Tarefa grafomorfológica flexional (Paula, 2007)}

Desenvolvida por Paula e Besse (Paula, 2007), a tarefa aborda a flexão de substantivos (variação de gênero) e verbos (tempos verbais), baseando-se no paradigma do intruso ${ }^{3}$. Para sua utilização nesta investigação, a tarefa teve seus itens adaptados da seguinte forma: foram apresentados 18 itens, sendo 6 para treino $(2$ com flexão de substantivo e 4 com flexão de verbo) e 12 experimentais ( 6 com flexão de gênero e 6 com flexão verbal de tempo: 3 passado/futuro e 3 presente/passado).

Para a realização da tarefa (que foi aplicada de forma impressa, conforme empregada pelas autoras da tarefa),

3 De acordo com Paula (2007): "este paradigma foi criado em Oxford, pela equipe de Peter Bryant no início dos anos 80 [...] e consiste em apresentar oralmente uma primeira palavra e depois outras duas, entre as quais 0 participante deverá escolher a que tem menos a ver com a primeira palavra" (p. 52). os alunos precisam encontrar qual entre duas palavras é diferente da palavra-chave apresentada. Três itens utilizados no treino são apresentados como exemplo:

- Qual é a palavra que não serve só para mulher como "esposa" (palavra-chave), "carioca" ou "garota"? Neste caso, o intruso é "carioca".

- Qual é a palavra que não indica uma ação passada como "trabalhei" (palavra-chave), "andarei" ou "encontrei"? Neste caso, o intruso é "andarei".

- Qual é a palavra que não indica uma ação presente como "festejam" (palavra-chave), "respiram" ou "mandaram"? Neste caso o intruso é "mandaram".

- A tarefa é composta de 12 itens de teste (Assim, 12 acertos $=100 \%, 11$ acertos $=91,67 \%$ ).

\section{Tarefa grafomorfológica derivacional (Paula, 2007)}

Esta tarefa também foi desenvolvida por Paula e Besse (Paula, 2007) e apresenta mesma estrutura da tarefa grafomorfológica flexional, pois também foi construída tendo como base o paradigma do intruso. Para a realização da tarefa o participante tem que decidir se uma palavra é construída da mesma forma que outra, a partir da explicação de como podemos obter palavras novas pelo acréscimo de um prefixo ou sufixo em uma palavra primitiva $a^{4}$. Por exemplo: a palavra desfazer vem de fazer pelo acréscimo do des- no início de fazer. Situação semelhante ocorre com chaveiro e chave, em que se acrescenta o -eiro no final de chave. Entretanto, para que o aluno possa discriminar uma palavra derivada de outra não derivada, apresenta-se como exemplo a palavra desperdiçar que possui a sílaba des na frente, mas não vem de perdiçar. Assim como a palavra chiqueiro não vem de chique. Após a explicação, os alunos realizam com o auxílio do aplicador os quatro itens de treino (dois envolvendo prefixos e dois envolvendo sufixos) em que devem encontrar qual entre duas palavras é diferente da palavrachave apresentada. A tarefa propriamente dita consiste de 6 grupos de 3 palavras envolvendo prefixos (ex.: desfazer) desperdiçar/descolorir; replantar/reservar/relembrar) e 6 grupos de 3 palavras envolvendo sufixos (ex.: chaveiro/chiqueiro/cinzeiro; protetor/autor/inventor). A tarefa é composta de 12 itens, 6 envolvendo prefixos e 6 envolvendo sufixos.

\section{Compreensão de leitura}

Para a avaliação da compreensão de leitura empregou-se a técnica de $\mathrm{Cloze}^{5}$ e foram apresentados dois textos

4 Os termos "palavra primitiva" e "palavra derivada" foram utilizados por Rocha (2008) para explicar que um falante nativo do português não deve apresentar dificuldade para identificar que palavras como leitoso, cabeludo e reinventar vêm de leite, cabelo e inventar (p. 98)

5 Conforme explica Santos (2004), o procedimento de Cloze foi proposto por Taylor em 1953 e tem sido utilizado tanto para o diagnóstico como para o desenvolvimento da compreensão de leitura. A autora acrescenta 
diferentes para cada um dos grupos de alunos. Destaca-se que a utilização de textos diferentes para a compreensão de leitura dos participantes deve-se ao fato de eles terem uma diferença de 2 anos de escolaridade e, supostamente, diferentes competências na leitura e compreensão dos textos. Portanto, foram utilizados textos com níveis de dificuldades diferentes.

Os textos apresentados aos alunos do $3^{\circ}$ ano foram adaptações de uma história contada pelo povo - "O pulo do gato" - e de uma fábula clássica - "O leão e o mosquito" (Barreto, n.d.). Os textos apresentam respectivamente o seguinte total de palavras (incluindo as lacunas): "O pulo do gato", 139 palavras; "O leão e o mosquito", 143 palavras. Os Clozes foram elaborados pela retirada sistemática do $9^{\circ}$ vocábulo de cada um dos textos, de forma que cada um deles ficou com 15 lacunas que deveriam ser preenchidas pelos examinandos.

Aos alunos do $4^{\circ}$ ano foram apresentados os textos: "O último dragão" (Elenice Machado de Almeida, citado por Morais, 1997) e "Um piquenique bem divertido" (Ruth Rocha, citado por Morais, 1997). Os textos contêm ao todo (incluindo as lacunas) respectivamente 156 palavras ("O último dragão") e 170 palavras ("Um piquenique bem divertido"). Estes Clozes foram aplicados exatamente como elaborados por Morais (1997), que preparou os textos omitindo vocábulos a partir da segunda sentença e com intervalos fixos de 5 palavras. Desta forma, o texto "O último dragão" apresentou 24 lacunas e o texto "Um piquenique bem divertido", 29 lacunas, que deveriam ser completadas pelos examinandos.

Os alunos do $5^{\circ}$ ano leram os textos "A Lontra" e "Os morcegos" (Saraiva, Moojen e Munarski, 2009). Os textos apresentam respectivamente o seguinte total de palavras (incluindo as lacunas): "A Lontra", 151 palavras; "Os morcegos", 200 palavras. Os Clozes foram elaborados pela retirada sistemática do $10^{\circ}$ vocábulo de cada um dos textos, de forma que o texto "A Lontra" ficou com 15 lacunas e o texto "Os morcegos" ficou com 20 lacunas, as quais deveriam ser preenchidas pelos examinandos.

Destaca-se que em nenhum dos Clozes é considerada as classes das palavras sobre as quais recai a omissão. Além disso, é importante salientar também que, para a correção dos testes de Cloze, foram considerados acertos os preenchimentos das lacunas com palavras que se encaixavam no texto de forma sintática e semanticamente correta.

\section{Procedimento}

Os alunos foram avaliados em três sessões. Conforme dito anteriormente, a produção escrita (reescrita do texto "O pote vazio") foi feita na própria sala de aula dos participantes e dirigida pelas professoras regentes das turmas. As outras duas sessões tiveram uma duração média

que "o Cloze consiste na organização de um texto, do qual se suprimem alguns vocábulos e se pede ao leitor que preencha os espaços com as palavras que melhor completarem o sentido do texto" (p. 218) de 20 minutos. A segunda sessão foi dividida em duas partes: primeiro, era feita uma aplicação coletiva (grupos de 4 alunos) da tarefa grafomorfológica flexional e de um Cloze. Em seguida os alunos, individualmente, resolviam a tarefa de categorização gramatical. Na última sessão, também em pequenos grupos, foi aplicada a tarefa grafomorfológica derivacional e o outro Cloze (conforme texto destinado ao ano escolar do participante).

\section{Resultados}

Como o número de acertos podia variar de acordo com as diferentes tarefas utilizadas neste estudo, todos os resultados serão apresentados em porcentagem. Primeiramente, os dados foram submetidos à prova de estatística descritiva, ou seja, foram calculados a média e respectivo desvio padrão do desempenho dos alunos dos 6 grupos em todas as tarefas realizadas. Na sequência, outras análises estatísticas foram feitas, mas como os grupos eram pequenos e a maioria dos instrumentos utilizados não era testes padronizados para a população em geral, optouse pelo uso de testes estatísticos não paramétricos (Siegel, 1975).

A Tabela 1 mostra a média da idade dos 72 participantes da pesquisa, bem como a média com o respectivo desvio padrão tanto dos percentuais de acertos na escrita das palavras (ortografia) ao reproduzir o texto escrito, como do percentual de acertos nos dois Cloze realizados e escore total de compreensão de leitura (obtido a partir da média do desempenho nos dois Cloze realizados).

Como se pode observar na Tabela 1 , tanto na tarefa de escrita como na de compreensão de leitura, os participantes dos Grupos A tiveram desempenho abaixo do desempenho dos alunos dos Grupos B. A comparação das médias obtidas pelos alunos utilizando a Prova U de MannWhitney mostrou que as diferenças de desempenho em escrita entre os grupos A e B dos três anos são significativas, ou seja, verificou-se para o $3^{\circ}$ ano $(U=0 ; p<0,001)$, para o $4^{\circ}$ ano $(U=0 ; p<0,001)$ e para o $5^{\circ}$ ano $(U=0 ; p<0,001)$. No que se refere à compreensão de leitura a utilização da mesma Prova U de Mann-Whitney, mostrou-se que apenas entre os alunos do $4^{\circ}$ e $5^{\circ}$ anos a diferença de desempenho entre os grupos A e B é significativa; ou seja, verificouse para o $3^{\circ}$ ano $(U=48,50 ; p=0,17)$, para o $4^{\circ}$ ano $(U=$ $15,00 ; p=0,001)$ e para o $5^{\circ}$ ano $(U=24,00 ; p<0,01)$.

A tabela 2 sumariza os resultados obtidos nas três tarefas de avaliação da consciência morfológica. Tais resultados indicam que em todas as tarefas o desempenho dos grupos A foi menor do que o desempenho dos grupos B.

Para comparar o desempenho dos alunos nas tarefas de avaliação da consciência morfológica também foi utilizada a Prova U de Mann-Whitney. Essa prova mostrou que, considerando-se o escore das três provas juntas, os desempenhos dos três pares de grupo A e B são significativamente diferentes, ou seja, as comparações entre os grupos apresentaram: para o $3^{\circ}$ ano $(U=34,00 ; p<0,05)$, 
Tabela 1

Média de idade dos participantes e média e desvio padrão dos percentuais de acertos na escrita e compreensão de leitura, por grupo

\begin{tabular}{|c|c|c|c|c|c|c|c|c|c|c|}
\hline \multirow[t]{2}{*}{ GRUPO } & \multirow{2}{*}{$\mathbf{N}$} & \multirow{2}{*}{$\begin{array}{l}\text { Idade } \\
\text { M. }\end{array}$} & \multicolumn{2}{|c|}{$\begin{array}{l}\text { Acertos na } \\
\text { Escrita }\end{array}$} & \multicolumn{2}{|c|}{ Acertos no Cloze 1} & \multicolumn{2}{|c|}{ Acertos no Cloze 2} & \multicolumn{2}{|c|}{$\begin{array}{c}\text { Escore de Compreensão } \\
\text { de leitura }\end{array}$} \\
\hline & & & M. & D.P. & M. & D.P. & M. & D.P. & M. & D.P. \\
\hline $3^{\circ} \mathrm{A}$ & 12 & 8a. $3 \mathrm{~m}$. & 67,15 & 10,03 & 22,22 & 13,43 & 43,88 & 26,73 & 33,05 & 18,93 \\
\hline $3^{\circ} \mathrm{B}$ & 12 & $8 \mathrm{a} .4 \mathrm{~m}$. & 86,25 & 5,94 & 31,67 & 19,08 & 56,68 & 23,03 & 44,18 & 20,26 \\
\hline $4^{\circ} \mathrm{A}$ & 12 & 9a. $2 \mathrm{~m}$. & 73,60 & 6,12 & 16,38 & 7,21 & 21,52 & 10,17 & 18,95 & 7,18 \\
\hline $4^{\circ} \mathrm{B}$ & 12 & 9a. $3 \mathrm{~m}$. & 89,80 & 5,48 & 40,51 & 17,21 & 44,43 & 16,51 & 42,47 & 15,76 \\
\hline $5^{\circ} \mathrm{A}$ & 12 & 9a. $11 \mathrm{~m}$. & 71,98 & 8,07 & 16,47 & 17,98 & 28,19 & 19,68 & 22,33 & 17,09 \\
\hline $5^{\circ} \mathrm{B}$ & 12 & 9a. $11 \mathrm{~m}$ & 89,34 & 4,82 & 41,64 & 17,10 & 45,00 & 15,07 & 43,32 & 14,96 \\
\hline Total & 72 & 9a. $2 \mathrm{~m}$. & 79,69 & 11,33 & & & & & 34,05 & 18,74 \\
\hline
\end{tabular}

Tabela 2

Média e desvio padrão dos percentuais de acertos nas três tarefas de avaliação da consciência morfológica e escore de consciência morfológica

Tarefas de consciência morfológica

\begin{tabular}{cccccccccc} 
GRUPO & N & \multicolumn{9}{c}{$\begin{array}{c}\text { Categorização } \\
\text { gramatical }\end{array}$} & \multicolumn{2}{c}{$\begin{array}{c}\text { Grafo-morfológica } \\
\text { flexional }\end{array}$} & $\begin{array}{c}\text { Grafo-morfológica } \\
\text { derivacional }\end{array}$ & \multicolumn{2}{c}{$\begin{array}{c}\text { Escore de Consciência } \\
\text { morfológica }\end{array}$} \\
\cline { 3 - 11 } & & M. & D.P. & M. & D.P. & M. & D.P. & M. & D.P. \\
\hline $3^{\circ} \mathrm{A}$ & 12 & 57,96 & 11,43 & 52,08 & 14,26 & 49,30 & 26,69 & 53,12 & 12,50 \\
\hline $3^{\circ} \mathrm{B}$ & 12 & 76,85 & 17,04 & 56,25 & 17,81 & 64,58 & 15,12 & 65,90 & 11,19 \\
\hline $4^{\circ} \mathrm{A}$ & 12 & 64,44 & 22,08 & 53,47 & 18,95 & 59,03 & 10,33 & 58,98 & 10,92 \\
\hline $4^{\circ} \mathrm{B}$ & 12 & 78,89 & 20,26 & 65,27 & 21,85 & 67,36 & 12,02 & 70,51 & 12,95 \\
\hline $5^{\circ} \mathrm{A}$ & 12 & 60,00 & 27,41 & 62,49 & 12,56 & 61,11 & 17,52 & 61,20 & 12,79 \\
\hline $5^{\circ} \mathrm{B}$ & 12 & 73,33 & 23,09 & 81,25 & 12,37 & 76,39 & 17,34 & 77,99 & 13,56 \\
\hline TTotal & 72 & 68,58 & 21,70 & 61,80 & 18,90 & 62,96 & 18,65 & 64,45 & 14,27 \\
\hline
\end{tabular}

para o $4^{\circ}$ ano $(\mathrm{U}=38,00 ; \mathrm{p}=0,05)$ e para o $5^{\circ}$ ano $(\mathrm{U}=$ $29,50 ; \mathrm{p}<0,05)$.

Assim, infere-se haver uma relação entre a consciência morfológica e os desempenhos dos alunos em escrita (ortográfica) e compreensão de leitura. Para verificar esta relação foi utilizada a prova de correlação de Spearman, cujos resultados são apresentados na tabela 3 .

Esta prova mostrou que o desempenho dos participantes em escrita correlaciona-se positiva e significativamente com o desempenho em todas as outras habilidades investigadas, ou seja, tanto com a compreensão de leitura $\left(\mathrm{r}_{\mathrm{s}}=0,57 ; \mathrm{p}<0,01^{* *}\right)$ como com o desempenho nas tarefas de categorização gramatical $\left(\mathrm{r}_{\mathrm{s}}=0,38 ; \mathrm{p}<\right.$ $\left.0,01^{* *}\right)$, grafomorfológica flexional $(\mathrm{r}=0,35 ; \mathrm{p}<0,01 * *)$ e grafomorfológica derivacional $\left(\mathrm{r}_{\mathrm{s}}=0,36 ; \mathrm{p}<0,01^{* *}\right)$. Além disso, a mesma prova mostrou que o desempenho dos participantes na compreensão de leitura também se correlaciona positiva e significativamente com o desempenho nas tarefas de categorização gramatical $\left(\mathrm{r}_{\mathrm{s}}=0,41 ; \mathrm{p}<0,01^{* *}\right)$, 
Tabela 3

Coeficientes de correlação de Spearman para as relações entre as variáveis investigadas

\begin{tabular}{c|c|c|c|c}
\hline & 2 & 3 & 4 & 5 \\
\hline 1. Escrita &, $57^{* *}$ &, $38^{* *}$ &, $35^{* *}$ &, $36^{* *}$ \\
2. Compreensão na leitura & &, $41^{* *}$ &, $42^{* *}$ &, $42^{* *}$ \\
$\begin{array}{c}\text { 3. Categorização gramatical } \\
\text { 4. Grafo-morfológica } \\
\text { Flexional }\end{array}$ & & &, $27^{*}$ &, $23^{*}$ \\
$\begin{array}{c}\text { 5. Grafo-morfológica } \\
\text { Derivacional }\end{array}$ & & & &, $26^{*}$ \\
\hline
\end{tabular}

$* \mathrm{p}<0,05 ; * * \mathrm{p}<0,01$ (2-tailed)

grafomorfológica flexional $\left(\mathrm{r}_{\mathrm{s}}=0,42 ; \mathrm{p}<0,01^{* *}\right)$ e grafomorfológica derivacional $\left(\mathrm{r}_{\mathrm{s}}=0,42 ; \mathrm{p}<0,01 * *\right)$.

Por último, foram feitas análises de regressão para verificar se os desempenhos dos participantes nas tarefas de consciência morfológica contribuíam para explicar seus desempenhos em ortografia e compreensão de leitura.

$\mathrm{Na}$ análise de regressão múltipla apresentada na Tabela 4, a variável dependente é o desempenho ortográfico na reprodução escrita do texto "O pote vazio" e as variáveis independentes são as porcentagens de acertos nas tarefas de categorização de palavras, grafomorfológica flexional e grafomorfológica derivacional. Os resultados da regressão efetuada mostram que o desempenho na tarefa de categorização de palavras não contribui significativamente para explicar a variância na capacidade ortográfica $(t=1,62 ; p=0,11)$. Entretanto, foram verificados resultados significativos tanto na tarefa grafomorfológica flexional $(\mathrm{t}$ $=1,99 ; \mathrm{p}<0,05)$ como na tarefa grafomorfológica derivacional $(\mathrm{t}=2,67 ; \mathrm{p}<0,01)$.

Tabela 4

Desempenho na escrita ortograficamente correta predito a partir do desempenho nas tarefas de categorização de palavras, grafomorfológica flexional e grafomorfológica derivacional

\begin{tabular}{cccc}
\hline & $\beta$ & $\mathrm{SE}$ & $\mathrm{t}$ \\
\hline Constante & $53,54^{* *}$ & 5,45 & 9,82 \\
\hline Categorização de palavras & 0,09 & 0,06 & 1,62 \\
\hline Grafomorfológica flexional & $0,14^{*}$ & 0,07 & 1,99 \\
\hline $\begin{array}{c}\text { Grafomorfológica } \\
\text { derivacional }\end{array}$ & $0,18^{* *}$ & 0,07 & 2,67 \\
\hline
\end{tabular}

Nota. $* \mathrm{p} \leq .05 ; * * \mathrm{p}<.01$

Os resultados obtidos apontam que, isoladamente, o desempenho na tarefa grafomorfológica flexional explica
$14,0 \%(\mathrm{~F}=11,43 ; \mathrm{gl}=1 ; \mathrm{p}=0,001)$ e o desempenho na grafomorfológica derivacional explica $17,6 \%(\mathrm{~F}=14,97$; gl $=1 ; \mathrm{p}<0,001)$ da variância do desempenho ortográfico. Ademais, consideradas conjuntamente, estas variáveis explicam $23,7 \%$ da variância $(\mathrm{F}=10,70 ; \mathrm{gl}=2 ; \mathrm{p}<0,001)$.

Em seguida foi realizada uma análise de regressão múltipla para avaliar a contribuição genuína de cada uma das variáveis (desempenho nas tarefas de consciência morfológica) na compreensão de leitura.

$\mathrm{Na}$ análise apresentada na Tabela 5, a variável dependente é o escore de compreensão de leitura e as variáveis independentes são as porcentagens de acertos nas tarefas de categorização de palavras, grafomorfológica flexional e grafomorfológica derivacional. Os resultados da regressão efetuada foram os seguintes: para a tarefa de categorização de palavras $(t=2,91 ; p<0,01)$, para a tarefa grafomorfológica flexional $(\mathrm{t}=2,07 ; \mathrm{p}<0,05) \mathrm{e}$ para a tarefa grafomorfológica derivacional $(\mathrm{t}=2,95 ; \mathrm{p}$ $<0,01$ ), ou seja, apontam que o desempenho de todas as tarefas de consciência morfológica contribui significativamente para explicar a variância na compreensão de leitura.

Os resultados obtidos apontam que, isoladamente, o desempenho na tarefa de categorização de palavras explica $18,6 \%(\mathrm{~F}=15,99 ; \mathrm{gl}=1 ; \mathrm{p}<0,001)$, o desempenho na tarefa grafomorfológica flexional explica $16,3 \%(\mathrm{~F}=13,65 ; \mathrm{gl}$ $=1 ; \mathrm{p}<0,001)$ e o desempenho na tarefa grafomorfológica derivacional explica 20,9\% ( $\mathrm{F}=18,45 ; \mathrm{gl}=1 ; \mathrm{p}<0,001)$ da variância na compreensão de leitura. Por último, verificou-se que, consideradas conjuntamente, estas variáveis explicam $35,8 \%$ da variância na compreensão $(\mathrm{F}=12,64$; $\mathrm{gl}=3 ; \mathrm{p}<0,001)$.

Tabela 5

Desempenho na compreensão de leitura predito a partir do desempenho nas tarefas de categorização de palavras, grafomorfológica flexional e grafomorfológica derivacional

\begin{tabular}{cccc}
\hline & $\beta$ & $\mathrm{SE}$ & $\mathrm{t}$ \\
\hline Constante & $-16,56^{*}$ & 8,43 & $-1,96$ \\
\hline $\begin{array}{c}\text { Categorização de } \\
\text { palavras }\end{array}$ & $0,26^{* *}$ & 0,09 & 2,91 \\
\hline $\begin{array}{c}\text { Grafomorfológica } \\
\text { flexional }\end{array}$ & $0,22^{*}$ & 0,10 & 2,07 \\
\hline $\begin{array}{c}\text { Grafomorfológica } \\
\text { derivacional }\end{array}$ & $0,31^{* *}$ & 0,10 & 2,95 \\
\hline
\end{tabular}

Nota. $* \mathrm{p} \leq .05 ; * * \mathrm{p}<.01$

\section{Discussão}

Este estudo teve como principal objetivo verificar as relações entre a consciência morfológica e o desempenho em ortografia e compreensão de leitura de alunos do $3^{\circ}, 4^{\circ}$ e $5^{\circ}$ anos de uma escola pública. 
Destacou-se, em primeiro lugar, que há um crescente corpo de pesquisas investigando estas relações e que tem revelado indícios da contribuição do processamento morfológico, tanto para a aquisição inicial da linguagem escrita (Carlisle, 2000; Deacon \& Kirby, 2004; Deacon et al., 2009; Nagy et al., 2006) como para o aperfeiçoamento ortográfico e a compreensão de leitura (Carlisle, 1988, 1996; Guimarães, 2011; Nunes et al., 1997; Queiroga et al., 2006). Vários estudos têm revelado que os efeitos da estrutura morfológica e da consciência morfológica sobre a aprendizagem da escrita nos anos iniciais de escolarização são inferiores aos efeitos da fonologia e da consciência fonológica (Mota et al., 2008). Isto não causa surpresa, tendo em vista que as unidades gráficas das línguas alfabéticas - as letras - representam sons abstratos e não unidades de significado, bem como que a atenção às relações grafo-fônicas permite a leitura e a produção escrita adequadas de boa parte das palavras da língua.

Entretanto, o desenvolvimento da escrita também recebe contribuição da morfologia, pois a escrita, além de representar os sons, representa também os significados da língua. Em outras palavras, a escrita combina o princípio fonográfico e o semiográfico, e este último permite que unidades gráficas correspondam a um significado. Sendo os morfemas as menores unidades de significação da língua, é esperado que seu conhecimento também exerça influência e seja influenciado pela aprendizagem da leitura e da escrita.

No estudo do presente artigo, foram utilizadas tarefas de julgamento para a avaliação da consciência morfológica devido ao fato de que elas são tarefas mais fáceis do que as tarefas de produção da resposta correta e, também, porque os estudos de Mota (2008a) e Paula (2007) indicaram que as crianças com dois anos de escolarização formal são capazes de fazer julgamentos sobre a morfologia da língua. Contudo, acredita-se que as tarefas aplicadas foram adequadas ao presente estudo, tendo em vista que elas discriminaram o desempenho dos alunos dos grupos A e B de todos os anos. Assim, foi possível verificar que as crianças dos grupos B - classificadas nestes grupos por apresentarem melhor desempenho em escrita - tiveram melhor desempenho em todas as tarefas de avaliação da consciência morfológica.

Verificou-se também que, de modo geral, ou seja, nas tarefas grafomorfológicas (flexional e derivacional) o desempenho dos alunos aumentou conforme aumentou seu nível de escolaridade. Entretanto, este fato não ocorreu em relação à tarefa de categorização gramatical. Como pode ser visto na tabela 2 , o desempenho dos alunos do grupo $4^{\circ}$ $\mathrm{B}$ foi o maior entre todos os participantes; logo, foi maior do que o dos alunos do $5^{\circ} \mathrm{B}$. Comparando-se os alunos dos grupos A (baixo desempenho ortográfico) nesta mesma tarefa, também se verifica maior desempenho no grupo $4^{\circ} \mathrm{A}$ do que no grupo $5^{\circ} \mathrm{A}$. Portanto, constata-se que na tarefa de categorização gramatical foram os alunos do $4^{\circ}$ ano que apresentaram melhor desempenho. Uma das hipóteses explicativas para estes resultados é que a "análise morfológica" seja conteúdo programático do $4^{\circ}$ ano e que, por estarem realizando este mesmo tipo de atividade em suas aulas regulares naquele momento, os alunos do $4^{\circ}$ ano apresentaram maior facilidade na realização da tarefa. Já os alunos do $5^{\circ}$ ano, embora tivessem recebido instruções a este respeito no ano precedente, não tinham este conhecimento consolidado. Destaca-se, entretanto, que esta hipótese deve ser considerada com cautela, tendo em vista que os dados analisados são oriundos de um estudo transversal.

Os resultados aqui apresentados fornecem evidência da relação positiva entre as variáveis avaliadas em relação ao avanço nos anos escolares, bem como da contribuição de diferentes aspectos da consciência morfológica no desempenho ortográfico e na compreensão de leitura. Assim, tomado o desempenho conjunto nas tarefas de morfológica flexional e derivacional, verificou-se que ele explica $23,7 \%$ da variação no desempenho ortográfico dos participantes. Ademais, quando se analisou a relação entre o desempenho nas tarefas de consciência morfológica (categorização gramatical, grafomorfológica flexional e grafomorfológica derivacional) e o desempenho em compreensão de leitura, verificou-se que tomados os desempenhos nas três tarefas em conjunto, ele explica $35,8 \%$ da variância de desempenho dos participantes na compreensão de leitura.

Uma das questões que tem intrigado os pesquisadores da área é determinar se as habilidades morfológicas auxiliam exclusivamente na ortografia das palavras, cujos morfemas foram explicitamente ensinados ou se podem influenciar também a compreensão de leitura de forma geral. A este respeito, Deacon et al. (2009) sugerem que, nos estágios iniciais da aprendizagem da escrita, a relação entre a habilidade morfológica e a escrita é dirigida (relacionase com as aprendizagens das palavras morfologicamente complexas), depois se estende para o uso destes mesmos morfemas em outras palavras e, finalmente, influencia a ortografia de modo geral. Destaca-se que estudos anteriores já haviam mostrado uma correlação entre consciência morfológica e habilidade de leitura em geral (Carlisle, 2000; Deacon \& Kirby, 2004).

\section{Conclusões}

Os resultados deste estudo corroboram o argumento de que a consciência morfológica influencia a ortografia e a compreensão de leitura de modo geral. É importante notar que, em todos os anos letivos investigados $\left(3^{\circ}, 4^{\circ}\right.$ e $5^{\circ}$ anos), os alunos que apresentaram maior escore em consciência morfológica foram justamente os que produziram os textos mais corretos ortograficamente e que apresentaram, também, melhor compreensão de leitura.

Entretanto, este estudo tem algumas limitações que restringem a força das conclusões apresentadas, embora estas limitações tragam embutidas sugestões para outras pesquisas.

Em primeiro lugar, salienta-se que tanto os itens da tarefa grafomorfológica flexional como os da tarefa grafomorfológica derivacional foram restritos a alguns casos 
particulares de flexão e derivação. Na tarefa grafomorfológica flexional os itens envolvendo flexão verbal foram restritos à discriminação de verbos na $1^{\mathrm{a}}$ pessoa do singular do pretérito perfeito/futuro do presente (trabalhei/andarei) e $3^{\text {a }}$ pessoa do plural do presente/pretérito perfeito (beliscam/sonharam). Em relação à tarefa grafomorfológica derivacional, os itens referem-se à identificação de palavras derivadas a partir de dois prefixos (des-, re-) e dois sufixos (-eiro, -or), ou seja, foi enfatizada a formação de palavras exclusivamente a partir do acréscimo de quatro afixos específicos. Sugere-se que em estudos futuros outros morfemas sejam investigados.

Em segundo lugar, não se pode deixar de apontar uma possível limitação na capacidade de as tarefas grafomorfológicas avaliarem as habilidades dos alunos referentes à morfologia flexional e derivacional, devido ao fato de que elas são tarefas de julgamento e as respostas aos itens propostos resumiam-se a uma escolha entre duas alternativas, o que aumenta a chance de acertos devido ao acaso - algo que poderá ser contornado com análise do nível de acaso levando-se em conta o número de opções de resposta disponíveis, uma vez que se trata de tarefa de julgamento com opções de resposta fechadas. Para estudos futuros sugere-se a utilização de tarefas em que os participantes devem "produzir" a resposta correta em lugar de apenas "reconhecê-la".

Além disso, Deacon e Kirby (2004) chamam atenção para o fato de que a consciência morfológica é parte das habilidades metalinguísticas e, portanto, partilha variância comum com a consciência fonológica. Para esses autores, estudos que investigam a consciência morfológica devem controlar a consciência fonológica. Nesse sentido, essa é uma limitação da presente investigação que deve ser sanada em estudos futuros.

Por último, dadas às relações encontradas entre o desempenho nas tarefas de consciência morfológica e o desempenho na ortografia e na compreensão de leitura, infere-se que esta relação deve-se principalmente ao aspecto semântico da morfologia. Ou seja, a contribuição da morfologia para o desenvolvimento da escrita não se limita a um automatismo de padrões ortográficos (sem sentido), mas está pautada em unidades de significado. Sugere-se a condução de estudos futuros que verifiquem o efeito do treino de habilidades de consciência morfológica sobre o aperfeiçoamento da escrita ortográfica e sobre a compreensão em leitura nas séries estudadas.

Assim, sugere-se também que, no processo de ensino-aprendizagem da linguagem escrita, o professor dê destaque para as habilidades metalinguísticas, entre elas as de consciência fonológica, morfológica e sintático-semântica. Isto porque há evidências de que tanto a aquisição inicial como o aperfeiçoamento da escrita dependem de conhecimentos acessíveis à consciência, ou seja, de habilidades de análise, reflexão e controle intencional de diferentes unidades linguísticas (fonemas, morfemas, palavras, frases e textos). Salienta-se deste modo a importância de que estas categorias de conhecimento linguístico sejam consideradas em termos de metas e planejamento de atividades didáticas nas aulas de português. A explicitação destes conhecimentos linguísticos e o convite ao pensar deliberado sobre sua utilidade específica para as diferentes atividades de leitura e escrita poderão diminuir o esforço e facilitar a sua compreensão e aprendizagem das crianças.

\section{Morphological awareness: what is its role in orthographic performance in orthography and reading compre- hension?}

Abstract: Morphological awareness refers to the ability of reflecting on the smallest units of meaning in a language and in using them intentionally in word structuring and recognition. In this study arguments are presented to support the idea that in Portuguese, as in other alphabetic languages, morphological awareness contributes to both reading comprehension and for orthographic performance. The participants were 72 students from 3rd through 5th grades in a Public School (Curitiba, Brazil), divided in two groups (for each grade) according to orthographic performance. The data collection involved the application of seven assessment tools, as follows: one for spelling, three for morphological awareness and two for reading comprehension. The analysis of empirical data shows that performance in the morphological awareness assessment tasks (inflectional and derivational) contributes significantly to explain the variance in the performance of the participants for both reading comprehension and orthographic writing.

Keywords: orthography, morphology (linguistics), metalinguistic development.

\section{Conscience morphologique: quel rôle exerce-t-elle sur les performances orthographiques et sur la com- préhension en lecture?}

Resumè: La conscience morphologique est l'habileté à réflechir sur les plus petites unités de signification de la langue et à utiliser ces unités intentionnellement dans la construction et la reconnaissance des mots. Nous présentons dans cette recherche des arguments qui appuient l'idée qu'en portugais, comme dans d'autres langues alphabétiques, la conscience morphologique contribue à la compréhension en lecture et aux performances orthographiques. 72 enfants scolarisés en 3ème, 4ème et 5ème année dans une école publique (Curitiba, PR) et répartis en deux groupes en fonction de leurs performances 
orthographiques ont participé à cette étude. Les sujets ont été soumis à plusieurs instruments d'évaluation : une tâche de production orthographique, trois de conscience morphologique et deux de compréhension en lecture de texte. L'analyse de données empiriques montre que les performances aux tâches d'évaluation de la conscience morphologique (flexionnelle et dérivationnelle) contribuent aussi bien à la variance observée en compréhension en lecture qu'à celle observée en production orthographique.

Mot-clés: orthographe, morphologie (linguistique), développement métalinguistique.

\section{Conciencia morfológica: ¿qué papel ejerce en el desempeño ortográfico y en la comprensión de la lectura?}

Resumen: La conciencia morfológica se refiere a la habilidad para reflexionar sobre las más pequeñas unidades de sentido de una lengua y utilizarlas intencionalmente en la estructuración y reconocimiento de las palabras. Son presentados argumentos que apoyan la idea de que en el portugués, como en otras lenguas alfabéticas, la conciencia morfológica contribuye tanto para la comprensión de lectura como para el desempeño ortográfico. Participaron 72 alumnos de $3^{\circ}, 4^{\circ}$ y $5^{\circ}$ año de una Escuela Pública (Curitiba-PR), cada año separado en dos grupos según el desempeño ortográfico. La recolección de datos envolvió la aplicación de siete instrumentos de evaluación, siendo: uno de ortografía; tres de conciencia morfológica y dos de comprensión de lectura de texto. El análisis de los datos empíricos presentados muestra que el desempeño en las tareas de evaluación de la consciencia morfológica (flexional y derivacional) contribuye significativamente para explicar la varianza de desempeño de los participantes en ambas habilidades, o sea, comprensión de lectura y escritura ortográfica.

Palabras clave: ortografía, morfología (lingüística), desarrollo metalingüístico.

\section{Referências}

Barreto, V. (n.d.). Poetizando, confabulando, historiando. São Paulo, SP: Veredas.

Bowers, P. N., \& Kirby, J. R. (2010). Effects of morphological instruction on vocabulary acquisition. Reading \& Writing, 23, 515-537.

Bradley, L., \& Bryant, P. E. (1983). Categorizing sounds and learning to read: A causal connection. Nature, 301, 419-421.

Câmara Jr., J. M. (1988). Estrutura da língua portuguesa (18a ed.). Petrópolis, RJ: Vozes.

Capovilla, A. G. S., \& Capovilla, F. C. (2000). Efeitos do treino de consciência fonológica em crianças com baixo nível socioeconômico. Psicologia: Reflexão e Crítica, 13(1), 7-24.

Cardoso-Martins, C. (1995). Sensitivity to rhymes, syllables, and phonemes in literacy acquisition in Portuguese. Reading Research Quarterly, 30(4), 808-827.

Carlisle, J. (1988). Knowledge of derivational morphology and spelling ability in fourth, six, and eight graders. Applied Psycholinguistics, 9, 247-266.

Carlisle, J. (1995). Morphological awareness and early reading achievement. In L. B. Feldman (Org.), Morphological aspects of language processing (pp. 189209). Hillsdale, NJ: Lawrence Erlbaum Associates.

Carlisle, J. (1996). An exploratory study of morphological errors in children's written stories. Reading and Writing, $8,61-72$.

Carlisle, J. (2000). Awareness of the structure and meaning of morphologically complex words: Impact on reading. Reading and Writing, 12, 169-190.
Colé, P., Marec-Breton, N., Royer, C., \& Gombert, J. E. (2003). Morphologie des mots et apprentissage de la lecture. Reeducation Orthophonic, 213, 57-60.

Deacon, S., \& Bryant, P. (2005). What young children do and do not know about the spelling of inflections and derivations. Developmental Science, 8(6), 583-594.

Deacon, S., \& Kirby, J. (2004). Morphological awareness: Just "more phonological"? the roles of morphological and phonological awareness in reading development. Applied Psycholinguistics, 25, 223-238.

Deacon, S. H., Kirby, J., \& Bell-Casselman, M. (2009). How robust is the contribution of morphological awareness to general spelling outcomes? Reading Psychology, 30(4), 301-318.

Demi. (2000). O pote vazio. São Paulo, SP: Martins Fontes.

Ferraz, D. T., Salomão, T. C., \& Paula, F. V. de. (2011). Padrões de segmentação linguística na leitura de palavras em voz alta. Anais do VIIII Congresso Brasileiro de Psicologia do Desenvolvimento. Brasília, DF: Associação Brasileira de Psicologia do Desenvolvimento.

Frith, U. (1985). Beneath the surface of developmental dyslexia. In K. E. Patterson, J. C. Marshall \& M. Coltheart (Eds.), Surface dyslexia: Neuropsychological and cognitive studies of phonological reading (pp. 301330). London: Routledge \& Kegan Paul.

Guimarães, S. R. K. (2003). Dificuldades no desenvolvimento da lectoescrita: o papel das habilidades metalinguísticas. Psicologia: Teoria e Pesquisa, 19(1), 33-45.

Guimarães, S. R. K. (2011). Relações entre capacidade de segmentação lexical, consciência morfossintática e 
desempenho em leitura e escrita. Psicologia: Teoria e Pesquisa, 27(1), 23-32.

Kato, M. A. (1999). O aprendizado da leitura ( $5^{\text {a }}$ ed.). São Paulo, SP: Martins Fontes.

Laroca, M. N. C. (2005). Manual de morfologia do Português. Campinas, SP: Pontes.

Maluf, M. R., \& Barrera, S. D. (1997). Consciência fonológica e linguagem escrita em pré-escolares. Psicologia: Reflexão e Crítica, 10(1), 125-145.

Marsh, G., Friedman, M., Welch, V., \& Desberg, P. (1981). A cognitive-developmental theory of reading acquisition. In G. MacKinnon \& T. Waller, Reading research advances in theory and practice (pp. 199-201). New York, NY: Academic Press.

Morais, A. M. P. (1997). A relação entre a consciência fonológica e as dificuldades de leitura. São Paulo, SP: Vetor.

Morais, J., Alegria, J., \& Content, A. (1987). The relationships between segmental analysis and alphabetic literacy: An interactive view. Cahiers de Psychologie Cognitive, $7(5), 415-438$.

Mota, M. M. (2008a). Algumas considerações a respeito do que as crianças sabem sobre a morfologia derivacional. Interação, 12(1) 115-123.

Mota, M. M. P. E. (2008b). Considerações sobre o papel da consciência morfológica nas dificuldades de leitura e escrita: uma revisão da literatura. Revista Semestral da Associação Brasileira de Psicologia Escolar $e$ Educacional, 12(2), 347-355.

Mota, M. M. P. E. (2010). Refletindo sobre o papel da consciência morfológica nas dificuldades de leitura e escrita. In S. R. K. Guimarães \& M. R. Maluf (Orgs.), Aprendizagem da linguagem escrita: contribuições da pesquisa (pp. 153-172). São Paulo, SP: Vetor.

Mota, M. M. P. E. , Anibal, L., \& Lima, S. (2008). A morfologia derivacional contribui para a leitura e escrita no Português? Psicologia: Reflexão e Crítica, 21(2), 311-318.

Mota, M. M., Dias, J., Mansur-Lisboa, S. F., Paiva, N., Silva, D. A., \& Besse, A. S. (2011). Desenvolvimento da consciência morfológica nos estágios iniciais da alfabetização. Psicologia: Reflexão e Crítica, 24(1), 1-7.

Nagy, W., Berninger, V., \& Abbot, R. (2006). Contributions of morphology beyond phonology to literacy outcome of upper elementary and middle-school students. Journal of Educational Psychology, 98(1), 134-147.
Nunes, T., Bryant, P., \& Bindman, M. (1997). Morphological strategies: Developmental stages and processes. Developmental Psychology, 33(4), 637-649.

Paula, F. V. (2007). Conhecimento morfológico implícito e explícito na linguagem escrita (Tese de Doutorado). Instituto de Psicologia, Universidade de São Paulo, São Paulo, SP.

Queiroga, B. A. M., Lins, M. B., \& Pereira, M. A. L. V. (2006). Conhecimento morfossintático e ortografia em crianças do ensino fundamental. Psicologia: Teoria $e$ Pesquisa, 22(1), 95-100.

Roazzi, A., \& Dowker, A. (1989). Consciência fonológica, rima e aprendizagem da leitura. Psicologia: Teoria $e$ Pesquisa, 5, 31-55.

Rocha, L. C. de A. (2008). Estruturas morfológicas do português ( $2^{\mathrm{a}}$ ed.). São Paulo, SP: Editora WMF.

Sá, J. L. N. (1999). A relação entre a consciência morfossintática e a escrita ortográfica (Dissertação de Mestrado). Instituto de Psicologia, Universidade Federal do Rio de Janeiro, RJ.

Sá, J. L. N. (2006). O desenvolvimento da escrita ortográfica em adultos tardiamente escolarizados (Tese de Doutorado). Instituto de Psicologia, Universidade Federal do Rio de Janeiro, RJ.

Santos, A. A. A. (2004). O cloze como técnica de diagnóstico e remediação da compreensão em leitura. Interação em Psicologia, 8(2), 217-226.

Saraiva, R. A., Moojen, S. M. P., \& Munarski, R. (2009). Avaliação da compreensão leitora de textos expositivos: para fonoaudiólogos e psicopedagogos. São Paulo, SP: Casa do Psicólogo.

Seymour, P. H. K., Aro, M., \& Erskine, J. M. (2003). Foundation literacy acquisition in European orthographies. British Journal of Psychology, 94, 143174.

Siegel, S. (1975). Estatística não paramétrica para as ciências do comportamento. São Paulo, SP: McGrawHill do Brasil. (Trabalho original publicado em 1956)

Silva, M. C. P. S., \& Koch, I. G. V. (2005). Linguística aplicada ao português: morfologia. São Paulo, SP: Cortez.

Sterling, C. (1991). Introduction to the psychology of spelling. In C. Sterling \& C. Robson (Orgs.), Psychology, spelling \& education (pp. 1-15). Adelaide, Australia: Multilingual Matters.

Tunmer, W. E. (1990). The role of language prediction skills in beginning reading. New Zealand Journal of Educational Studies, 25(2), 95-114. 